\title{
Efeitos de tarefas de seleção na nomeação de figuras com crianças de 19 a 29 meses
}

\author{
Gabriela Aniceto \\ Lidia Maria Marson Postalli
}

\section{RESUMO}

Investigou-se se a exposição às tarefas de seleção de figuras diante das palavras ditadas seria condição suficiente para emergência de nomeação de figuras. Participaram quatro crianças na faixa etária de 19 a 29 meses com desenvolvimento típico. Utilizou-se o delineamento de múltiplas sondagens entre categorias (animais, frutas e brinquedos). Foi realizada a avaliação de nomeação com os estímulos das categorias; em seguida, foram realizadas as sessões de ensino da relação entre palavra ditada e figura e sonda de nomeação com a primeira categoria. Após atingir o critério estabelecido, foi realizada a avaliação da nomeação. O procedimento foi repetido com as duas demais categorias. Os resultados demonstraram que o ensino de seleção pode favorecer a nomeação de figuras. Verificou-se variabilidade intra e interparticipantes no desempenho em uma mesma categoria e entre categorias. Sugere-se replicações para avaliar a generalidade dos resultados e as variáveis que contribuam para aprimorar o procedimento de ensino.

Palavras-chaves: matching-to-sample; nomeação; crianças

\section{ABSTRACT}

It was investigated whether the exposure to the selecting figures tasks of dictated words would be sufficient condition for the emergence of naming figures. Four children in the age group of 19 to 29 months old with typical development participated in. It was used the multiple-probing design between categories (animals, fruits and toys). The evaluation was accomplished with the stimuli of the categories; then, the teaching sessions regarding the relation between dictation and figure; as well as the nomination probe with the first category. A nomination evaluation was accomplished after the established criteria. The procedure was repeated with two other categories. The results showed that the selection teaching may favor the naming of figures. Intra and interparticipants variability were verified in the performance of a same category and between categories. Replications are suggested to evaluate the generality of the results and as variables that contribute to the improvement of teaching.

Keywords: matching-to-sample; naming; children

Desde idade precoce, os bebês são capazes de distinguir entre os sons básicos de sua língua natural e de outras línguas (Oliveira \& Gil, 2007). A mais simples e importante habilidade para aumentar o interesse das crianças de se comunicarem é a intenção comunicativa, considerada, em muitas abordagens, como precursora da linguagem e da fala ou, como denominado por Skinner, dos operantes verbais (Greer \& Ross, 2008; Oliveira \& Gil, 2007). Desse modo, as respostas dos adultos, contingentes às intenções comunicativas da criança, são condições para que ela continue a produzir intenções comunicativas, uma vez que é por meio desse contexto interacional que as crianças entendem que produzir sons, em função da reação das pessoas, causa um impacto no ambiente (Aquino \& Salomão, 2010; Oliveira \& Gil, 2007).

Quando o adulto responde as intenções da criança, ela passa a compreender,

\section{Sobre os Autores}

G. A.

orcid.org/0000-0001-8230-9324

Universidade Federal de São

Carlos - São Carlos, SP

gabi.aniceto@hotmail.com

\section{M. M. P.}

orcid.org/0000-0001-7560-697X Universidade Federal de São

Carlos - São Carlos, SP

lidiapostalli@ufscar.com

\section{Direitos Autorais}

Este é um artigo de acesso aberto e pode ser reproduzido livremente, distribuído, transmitido ou modificado, por qualquer pessoa desde que usado sem fins comerciais. 0 trabalho é disponibilizado sob a licença Creative Commons CCBY-NC. 


\section{-4* INTERACÃO EM F PSICOLOGIA}

progressivamente, a relação arbitrária entre o nome falado e o objeto. De acordo com a literatura (Bee \& Boyd, 2011; Hoff, 1996; Newcombe, 1999), estima-se que as crianças com desenvolvimento típico pronunciam as primeiras palavras simples na faixa etária de 10 a 18 meses. Constata-se ainda que entre 13 e 14 meses a criança possui em seu repertório uma média de 10 palavras, entre 17 e 18 meses há uma estimativa de 50 palavras e aos 24 meses, estima-se que o repertório do bebê é composto por volta de 200 a 300 palavras (Acredolo \& Goodwyn, 1988; Bates, 1979; Goodwyn, Acredolo, \& Brown, 2000; Oliveira \& Gil, 2007).

A linguagem tem a comunicação como a primeira função, sendo por meio dela que as crianças estabelecem e mantêm interações com os outros indivíduos, comunicando suas necessidades, vontades, ideias, entre outros (McLaughlin, 2010). Entretanto, para que as interações sejam estabelecidas e mantidas, a comunidade verbal precisa compreender o falante. Para Skinner (1957), o comportamento verbal é considerado um comportamento operante que é mediado por um ouvinte - especialmente ensinado pela comunidade verbal, capaz de produzir alteração no ambiente, afetando o comportamento de outro indivíduo. No caso específico das crianças, o ouvinte deve ser capaz de compreendê-la e atendê-la, possibilitando o aprendizado e a manutenção da interação comunicativa.

O comportamento de ouvinte precede a aquisição do comportamento de falante, considerando que mesmo antes de as crianças começarem a falar, elas estabelecem a relação entre os nomes, que a sua comunidade verbal utiliza, e objetos, situações e ações por meio das interações, de forma que a probabilidade de ocorrência do evento futuro está diretamente relacionada às relações dentro da comunidade (Skinner, 1957). Para Greer e Speckman (2009), o indivíduo torna-se verbal quando desenvolve a capacidade de falante. As crianças estão expostas cotidianamente a situações em que ouvem um adulto dizendo um nome diante de um determinado objeto ou evento, por exemplo, quando um adulto diz bola diante do objeto bola. Nessa situação, a comunidade verbal está criando oportunidades para ensinar a criança a relação entre nome e objeto, sendo que diante de uma nova oportunidade de ouvir a palavra bola, a criança pode buscar pelo objeto, também pode nomear bola diante do objeto bola ou de outros eventos em que haja a presença de bola (Löhr \& Gil, 2015; Oliveira \& Gil, 2007).

Considerando os diferentes procedimentos de ensino dos comportamentos de ouvinte e de falante, há estudos que utilizam tarefas de seleção e nomeação dos operantes verbais mando e tato com diferentes populações e em diferentes idades (Anastácio-Pessan, Almeida-Verdu, Bevilacqua, \& Souza, 2015; Arntzen \& Almas, 2002; Bandini,

\section{Gabriela Aniceto e Lidia Maria Marson Postalli}

Sella, Postalli, Bandini, \& Silva, 2012; Carroll \& Hesse, 1987; Gomes, Benitez, Domeniconi, \& Almeida-Verdu, 2017; Gurteen, Horne, \& Erjavec, 2011; Hussein, Góes, Chiodelli, Silva-Marinho, Gonçalves, \& Almeida-Verdu, 2018; Lamarre \& Holland, 1985; Petursdottir, Carr, \& Michael, 2005; Santos, Neves, Silva, \& Almeida-Verdu, 2014; Santos \& Souza, 2016; Sousa, Souza, \& Gil, 2013). Alguns desses estudos utilizaram o procedimento de emparelhamento de acordo com modelo (matching to sample) para o ensino de discriminação condicional auditivo-visual (entre pseudopalavras e figuras abstratas) e testaram a nomeação das figuras, apresentando uma a uma. No estudo de Bandini et al. (2012), realizado com crianças entre 7 e 12 anos, as autoras indicaram que o ensino de discriminações condicionais pode facilitar a nomeação e destacaram que a quantidade de treino da relação palavra ditada e figura é uma variável importante a ser investigada.

Trabalhando com uma idade menor, se comparado à faixa etária dos participantes do estudo de Bandini et al. (2012), e com um procedimento de ensino semelhante ao empregado por Bandini et al. (2012), no estudo de Sousa et al. (2013), investigou-se os efeitos da combinação dos procedimentos de emparelhamento simultâneo de um estímulo auditivo e um estímulo visual e de emparelhamento com o modelo sobre a aprendizagem de comportamento de ouvinte por um bebê de 17 meses. Nas sessões de linha de base, a experimentadora selecionou algumas figuras de um livro infantil e, posteriormente, solicitou que a bebê as nomeasse. Os estímulos experimentais eram apresentados no meio do livro e a nomeação solicitada. Durante o procedimento de PVA, as figuras eram apresentadas uma por vez, sendo que, ao bebê tocar a figura, a pesquisadora dizia o nome da figura. A participante aprendeu a resposta de escolha da fotografia em uma única sessão de ensino (pareamento estímulo auditivo-estímulo visual) e as relações condicionais nomefoto em 14 sessões de ensino. Conforme indicado pelos autores, estudos futuros deveriam controlar a quantidade de exposição dos estímulos a serem nomeados e realizar avaliações repetidas do repertório dos participantes.

Santos e Souza (2016) trabalharam com crianças com autismo com idade entre 5 e 9 anos. O procedimento foi composto de treino de seleção e teste de nomeação para os dois tipos de estímulos (bidimensionais e tridimensionais). 0 delineamento consistiu na avaliação da nomeação de linha de base, treino de discriminação condicional por identidade com a nomeação do estímulo pelo experimentador, discriminação auditivo-visual e nomeação de novos estímulos seguida de uma avaliação de nomeação. Eram intercaladas as sessões com os estímulos bidimensionais e tridimensionais. Das quatro crianças participantes, duas demonstraram a nomeação dos estímulos bidimensionais. Os autores indicaram a importância dos estudos que avaliam 


\section{W INERACÄOEM ET PSICOLOGIA}

Gabriela Aniceto e Lidia Maria Marson Postalli a aprendizagem considerando a natureza dos estímulos empregados e a interação entre repertórios de ouvinte e falante.

Considerando a necessidade de estudos que investiguem a interação entre repertórios de ouvinte e de falante e a importância de manipulações de variáveis para aprimorar o controle experimental, o presente estudo teve como objetivo investigar se a exposição a tarefas de seleção de figuras diante de palavras ditadas (tarefas envolvendo repertório de ouvinte) seria condição suficiente para a emergência da nomeação de figuras (repertório de falante) por crianças na faixa etária de 19 a 29 meses.

\section{MÉTODO}

\section{PARTICIPANTES}

Participaram desta pesquisa quatro crianças com desenvolvimento típico na faixa etária de 19 a 29 meses que frequentavam uma creche pública de uma cidade de médio porte do interior de São Paulo. A pesquisa foi aprovada pelo Comitê de Ética em Pesquisa com Seres Humanos da Universidade Federal de São Carlos (CAEE no 70579517.6.0000.5504).

Tabela 1. Caracterização dos participantes de acordo com a idade, sexo e desempenho no Teste de Triagem de Desenvolvimento de Denver II e no Teste de Vocabulário Expressivo (TVExp-100r) e Receptivo (TVAud-a33o)

\begin{tabular}{cccccc}
\hline Participante & $\begin{array}{c}\text { Idade } \\
\text { (em meses })\end{array}$ & Sexo & Denver & TVExp-100r & TVAud-a33o \\
\hline P1 & 19 & M & Normal & Muito rebaixado & Muito rebaixado \\
P2 & 24 & F & Normal & Muito rebaixado & Muito rebaixado \\
P3 & 27 & M & Normal & Rebaixado & Médio \\
P4 & 29 & F & Normal & Rebaixado & Médio \\
\hline
\end{tabular}

De acordo com o Teste de Triagem de Desenvolvimento de Denver II (Frankenburg, Dodds, Archer, Shapiro, \& Bresnick, 1992), nenhuma das crianças apresentou risco para o desenvolvimento, obtendo a classificação normal. Além de avaliar o desenvolvimento global dos participantes, foi realizado um levantamento de repertório do vocabulário expressivo (TVExp-100r; Capovilla, Negrão, \& Damázio, 2011), sendo o repertório de P1 e P2 classificado como muito rebaixado e de $\mathrm{P} 3$ e $\mathrm{P} 4$ como rebaixado, de acordo com nomenclatura do instrumento. $\mathrm{Na}$ avaliação do vocabulário receptivo (TVAud-a33o; Capovilla et al., 2011), P1 e P2 apresentaram um vocabulário muito rebaixado e P3 e P4 foram classificados com repertório médio.

\section{SITUAÇÃO EXPERIMENTAL}

A pesquisa foi realizada na instituição frequentada pelas crianças e as sessões de coleta de dados ocorreram em uma sala disponibilizada para uso da pesquisadora.

As atividades foram conduzidas sobre um tapete de EVA, garantindo o conforto e segurança das crianças. Os estímulos utilizados foram auditivos (palavra ditada pela pesquisadora) e visuais (figuras ilustrativas coloridas impressas e plastificadas no tamanho de $11,5 \times 16 \mathrm{~cm}$ ). Para registro das atividades foram utilizados uma filmadora em um tripé.

\section{ESTIMULOS}

As categorias escolhidas para a realização da pesquisa foram aquelas supostamente familiares paras as crianças pequenas, a saber: animais, frutas e brinquedos. Os estímulos que compuseram cada categoria foram escolhidos por serem potencialmente familiares para as crianças, porém não nomeados por elas. Os estímulos foram apresentados em pares. A categoria animais foi composta pelos estímulos rena/tatu e foca/peru; a categoria de frutas foi constituída pelos estímulos pera/coco e figo/caju; a categoria brinquedos foi formada pelos estímulos pipa/dado e dominó/peteca.

\section{DELINEAMENTO EXPERIMENTAL}

No presente estudo, adotou-se um delineamento de múltiplas sondagens entre categorias de estímulos (Gast \& Ledford, 2010), mantendo o mesmo comportamento medido (variável dependente) e os mesmos participantes. Foram realizadas sessões de ensino (ensino de seleção) e sessões de sondagem (testes de nomeação) para verificação dos efeitos de tarefas de seleção na nomeação de figuras. 


\section{W INERACÄOEM ET PSICOLOGIA}

\section{PROCEDIMENTO DE COLETA DE DADOS}

Inicialmente, foi realizada a avaliação de nomeação com os estímulos das três categorias. Em seguida, foi realizada a fase de ensino e teste da primeira categoria. Após o critério estabelecido, foi novamente realizada a avaliação de nomeação com os estímulos das três categorias. Foi realizada a fase de ensino e teste com os estímulos da segunda categoria até o critério, seguida pela avaliação de nomeação com os estímulos das três categorias. Posteriormente, foi realizada a fase de ensino e teste com a terceira categoria, seguida pela avaliação de nomeação com os estímulos das três categorias.

\section{AVALIAÇÃO DA NOMEAÇÃO COM OS ESTÍMULOS DAS TRÊS CATEGORIAS}

A avaliação de nomeação consistiu em três sessões iniciais que evidenciaram um critério de estabilidade e/ou tendência de desempenho. Cada sessão foi composta por 12 tentativas, uma com cada figura das três categorias. As figuras foram apresentadas pela pesquisadora para cada criança. A instrução apresentada pela pesquisadora foi "O que é isso?"/"Quem é esse?", a criança deveria responder verbalmente. Após a resposta, a pesquisadora recolhia a figura e o mesmo procedimento foi repetido com outro estímulo. Não foram programadas consequências diferenciais para acertos e erros. Para manter a participação da criança na tarefa, a pesquisadora apresentava consequências sociais com valor reforçador, por exemplo, "Continua prestando atenção" e "Vamos ver o próximo?".

Essa mesma avaliação foi conduzida após o ensino de cada categoria e serviu de linha de base para as categorias não ensinadas e de avaliação de aprendizagem e de manutenção para as categorias ensinadas.

\section{PROCEDIMENTO DE ENSINO E TESTE DE NOMEAÇÃO}

Ensino de discriminações condicionais auditivo-visual e teste de nomeação

0 procedimento de ensino consistiu em expor a criança ao ensino de seleção de figura diante de um estímulo auditivo para depois testar a nomeação da figura. Quatro elementos de cada categoria (animais, brinquedos e frutas) foram ensinados par a par, dois pares de cada categoria. Cada sessão foi composta por blocos de ensino de seleção alternados com blocos de teste de nomeação.

Ensino de seleção: consistiu na apresentação de dois estímulos visuais dispostos na frente da criança. Diante da instrução auditiva da pesquisadora "Qual é... (nome da figura)" ou "Põe o dedinho... (nome da figura)", a criança
Gabriela Aniceto e Lidia Maria Marson Postalli

deveria selecionar o estímulo visual que correspondesse ao estímulo auditivo. Na ausência de resposta, após 5 segundos, a instrução foi repetida. A resposta correta foi seguida de um elogio pela pesquisadora e a repetição do nome do estímulo "Esse aqui é o/a... (nome da figura)". A resposta incorreta, ou a ausência de resposta (após a repetição instrução), foi seguida pela apresentação da próxima tentativa pela pesquisadora. A fim de diminuir as probabilidades de escolha por posição, os estímulos visuais foram apresentados aleatoriamente. Cada bloco de ensino foi composto por seis tentativas (três com cada estímulo do par). O critério para realizar o teste de nomeação foi de $100 \%$ de acertos no bloco de seleção. Se a porcentagem de acerto fosse menor que $100 \%$, a criança refazia o bloco de ensino de seleção.

Teste de nomeação: consistiu na apresentação de um estímulo visual simultaneamente a pergunta da pesquisadora, "O que é isso?", e a criança deveria responder verbalmente. Na ausência de resposta, após 5 segundos, a instrução foi repetida. Não foram programadas consequências para acerto e erro. Cada bloco de tentativas foi composto por seis tentativas (três com cada estímulo). 0 critério de aprendizagem foi de $100 \%$ de acertos nas tentativas de um bloco de nomeação. No caso de atingir o critério, a criança realizava o ensino de seleção e o teste de nomeação com um novo par de estímulos. Caso o participante não atingisse o critério, um novo bloco de ensino do mesmo par foi repetido. Na Figura 1 é apresentado o fluxograma da sessão composto por blocos de seleção e blocos de teste de nomeação. 0 critério exigido para iniciar o ensino e o teste com um novo par de estímulos foi de $100 \%$ de acertos na nomeação ou quatro repetições da sessão com o mesmo par de estímulos.

Após atingir o critério com os dois pares de estímulos de uma categoria, a avaliação de nomeação com os estímulos das três categorias era reconduzida. Os procedimentos de ensino de seleção e de teste de nomeação foram repetidos para os pares das três categorias (animais, brinquedos e frutas) e com os mesmos critérios.

\section{PROCEDIMENTO DE ANÁLISE DOS DADOS}

Os dados registrados em anotações realizadas durante a coleta de dados (protocolo de acerto) nas tarefas experimentais foram analisados e conferidos com o auxílio das filmagens. Foi realizada a análise gradual do desempenho individual nos blocos de ensino de seleção e nos blocos de teste de nomeação de figuras em termos de acertos e de quantidade de sessões e/ou blocos requeridas para atingir os critérios estabelecidos.

Foi realizada uma análise das vocalizações apresentadas na nomeação dos estímulos, considerando que algumas 


\section{INTERACÃO EM LF PSICOLOGIA}

variações fonológicas poderiam ser encontradas em crianças de 19 a 29 meses, de acordo com Lamprecht et al. (2004). Para análise dos resultados e classificação dos desempenhos, as respostas foram categorizadas, de acordo com Souza, Almeida-Verdu, e Bevilacqua (2013), em: i) acertos: foram consideradas as palavras vocalizadas nas tentativas de nomeação de figuras com correspondência ponto a ponto com o nome da figura apresentada pela pesquisadora; ii) trocas: foram consideradas as palavras vocalizadas com correspondência parcial com o nome da figura apresentado pela pesquisadora, como na substituição
Gabriela Aniceto e Lidia Maria Marson Postalli de um fonema por outro - exemplo: sato no lugar de sapo; iii) omissões: foram consideradas quando o participante não emitia todos os fonemas do nome da figura apresentada pela pesquisadora - exemplo: minó ao invés de dominó; iv) nenhuma resposta: foi considerada quando o participante, nas tentativas de nomeação, não emitia nenhuma resposta diante da apresentação de uma figura pela pesquisadora; e v) outra palavra: foram consideradas as respostas emitidas diante de uma figura em que a criança emitia outro nome daquele usado para nomear a figura - exemplo: au-au no lugar de foca.

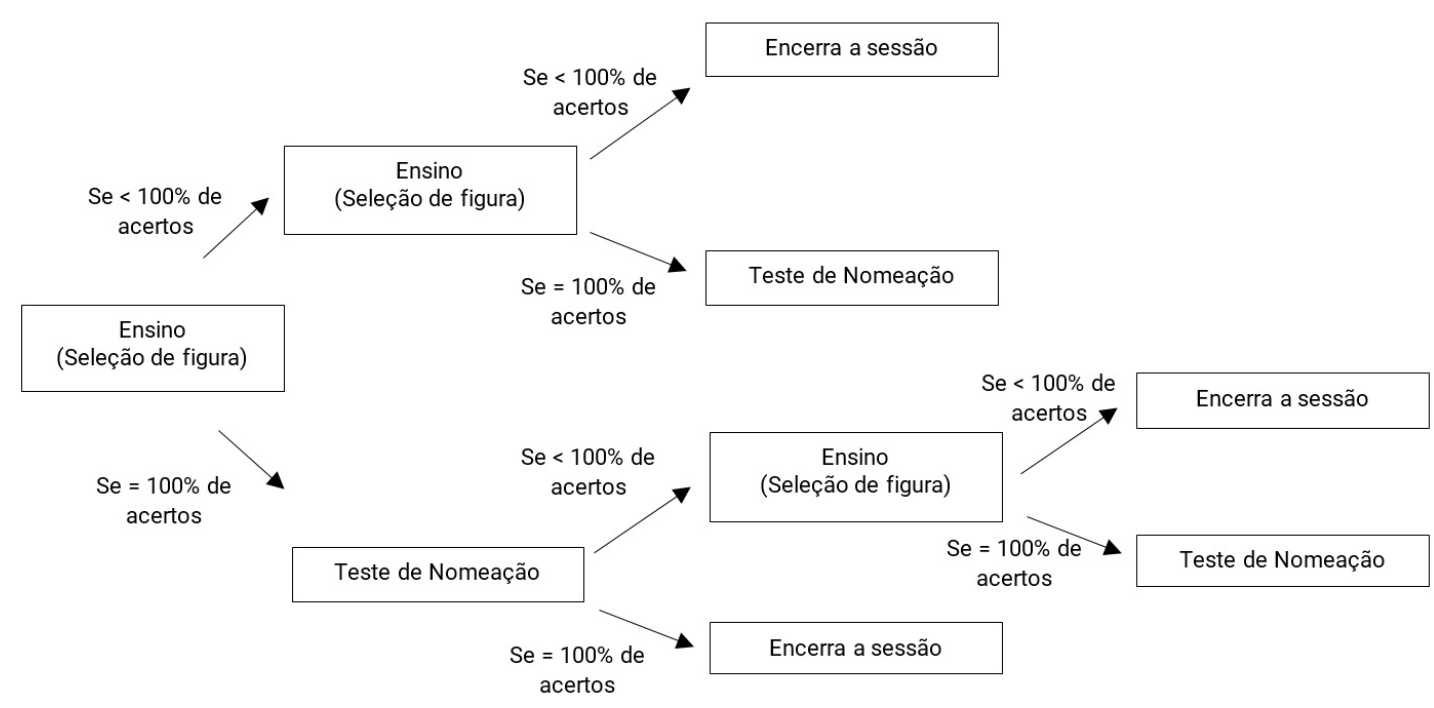

Figura 1. Fluxograma de uma sessão de ensino de seleção e de teste de nomeação. Cada bloco de ensino e de teste foi composto por seis tentativas. O critério para realizar um novo par de estímulos foi de $100 \%$ de acertos na nomeação ou quatro repetições do procedimento com o mesmo par de estímulos.

\section{CONCORDÂNCIA ENTRE OBSERVADORES}

A concordância entre observadores para tarefas de nomeação em avaliações das três categorias foi calculada usando as filmagens das sessões. Um segundo observador, que estava ciente do objetivo do estudo, assistiu às gravações e registrou as respostas de $30 \%$ das sessões de cada participante para estabelecer o índice de concordância entre observadores, empregando a fórmula na qual o número de tentativas em que houve concordância entre os observadores é dividido pelo número total de tentativas (concordância somada à discordância) e multiplicado o resultado por 100 (Kazdin, 1982). Foi utilizado como critério para avaliar a concordância, a classificação de Souza et al. (2013) (acertos; trocas; omissões; nenhuma resposta; outra palavra). Para P1, o índice calculado foi $98 \%$; para P2 foi de 98\%; para P3 foi de $100 \%$; e para P4 foi de $99 \%$.

\section{RESULTADOS}

Na Figura 2 é apresentado o desempenho dos participantes no ensino de seleção de figuras (barras) e no teste de nomeação de figuras (círculos) com estímulos dos conjuntos utilizados no procedimento. As barras e os pontos representam a porcentagem de acertos obtida em cada bloco de ensino ou de teste. A seta em P1 indica a realização de ensino remediativo. Na primeira avaliação de nomeação das figuras das três categorias e na tarefa de nomeação da primeira categoria, a nomeação apresentada pelo participante foi repetida pela pesquisadora. A partir da segunda avaliação, após a nomeação de um estímulo, o próximo estímulo foi apresentado sem a repetição do nome do estímulo pela pesquisadora.

De acordo com a Figura 2, P1 não nomeou corretamente os estímulos apresentados em nenhuma das três categorias. $\mathrm{Na}$ categoria animais, para o primeiro par de estímulos 
P1
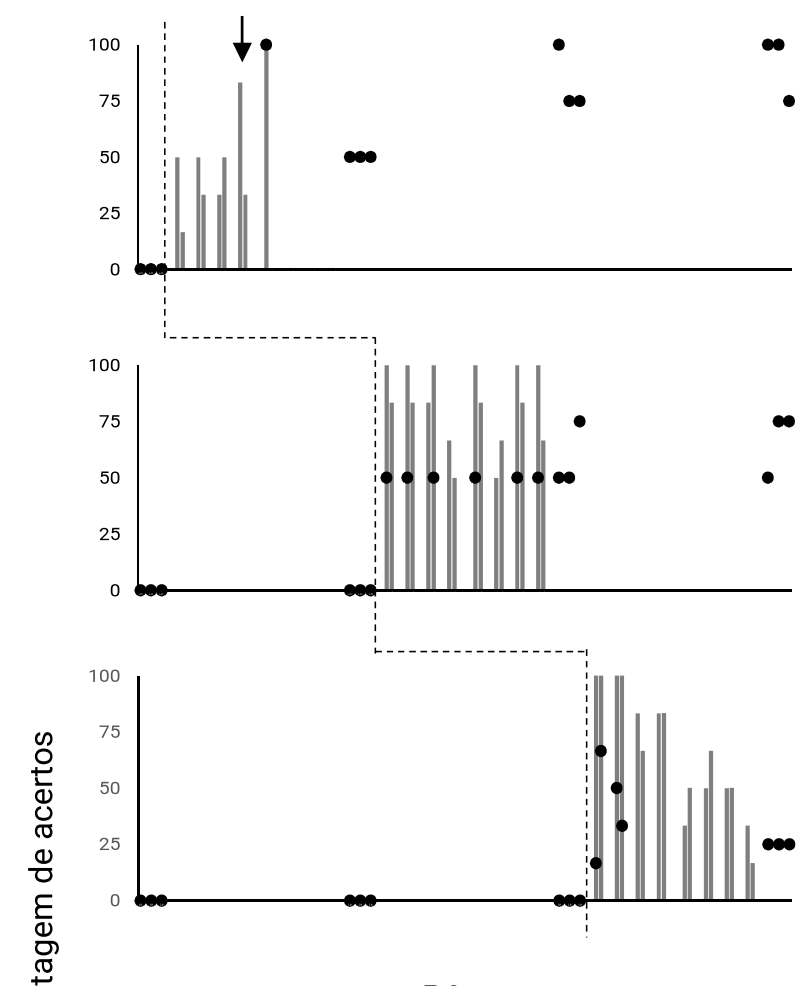

P3

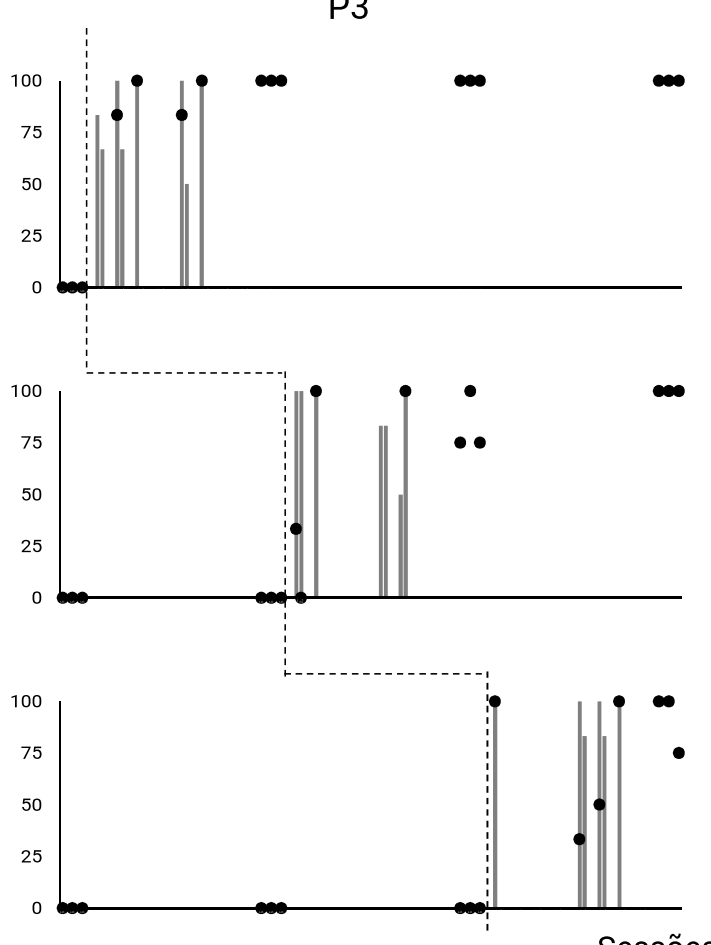

P2
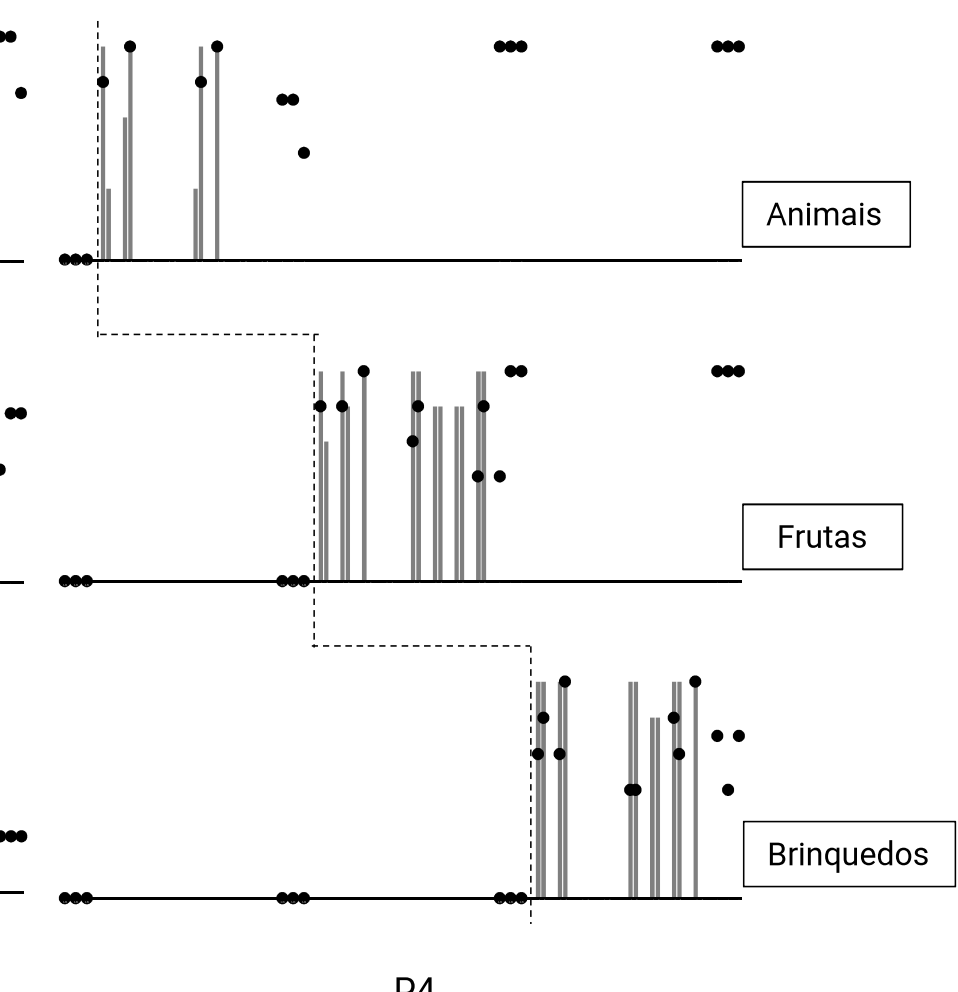

P4
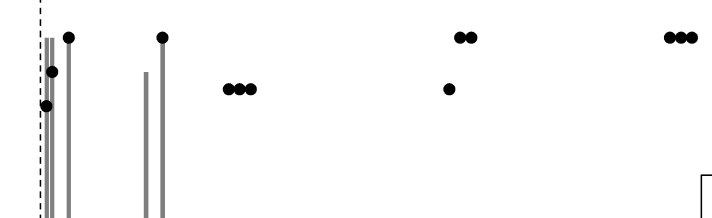

$\bullet$
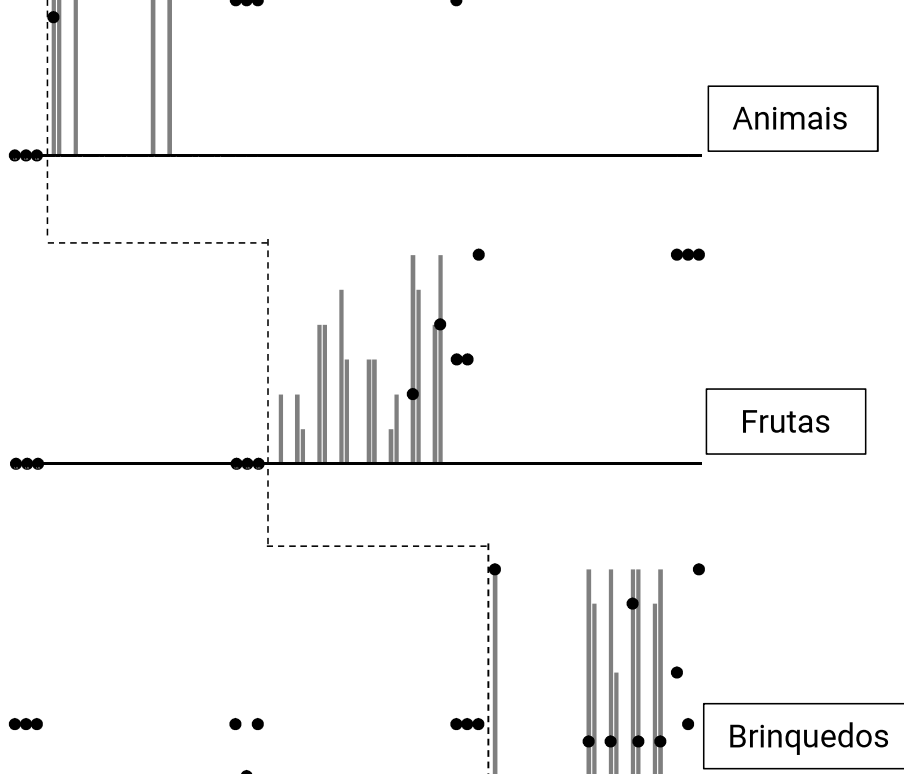

Sessões consecutivas

Figura 2. Porcentagem de acertos apresentada pelos participantes no ensino de seleção de figuras (barras) e de teste de nomeação de figuras (pontos) nas categorias de animais, frutas e brinquedos. As linhas tracejadas indicam os desempenhos antes do ensino (à esquerda) e após o ensino (à direta). A seta em P1 indica realização do ensino remediativo. 


\section{-4* INTERACÃO EM F PSICOLOGIA}

apresentado (foca/peru), P1 não atingiu o critério em nenhum dos blocos de seleção das quatro sessões de ensino, não sendo assim submetido ao teste de nomeação. Diante desse desempenho, o participante foi exposto a uma sessão, com dois blocos com seis tentativas cada, de discriminação condicional auditivo-visual com os estímulos sol e carro (nomeados por ele na avaliação do repertório expressivo), antes de iniciar o ensino do segundo par de estímulos da categoria animal. Após uma sessão, o participante atingiu $100 \%$ de acertos tanto no ensino de seleção quanto no teste de nomeação. Na sonda de aprendizagem (avaliação de nomeação dos estímulos das três categorias), a criança apresentou $50 \%$ de acertos na nomeação dos estímulos ensinados e manteve o desempenho nulo para os estímulos das demais categorias. Na categoria frutas, P1 realizou quatro sessões com cada par de estímulos, realizando o teste de nomeação três vezes com o primeiro par (pera/coco) e duas vezes com o segundo par (figo/caju), até atingir o critério máximo de repetição com cada par, sem apresentar nomeação consistente dos estímulos dos pares da categoria fruta. Após o encerramento da categoria, na sonda de aprendizagem, verificou-se que o participante apresentou aumento do percentual de nomeação correta dos estímulos das categorias animais e frutas e manteve o desempenho nulo na categoria brinquedos (não ensinada). Para a categoria brinquedos, P1 atingiu o critério em blocos de seleção nas duas primeiras sessões das quatros sessões de seleção do primeiro par de brinquedos (pipa/dado) ensinado. No entanto, P1 não atingiu o critério nos testes de nomeação dessas duas sessões. Em relação ao segundo par (peteca/ dominó), o participante não atingiu o critério em nenhum dos blocos de seleção. Na terceira avaliação de nomeação, notouse que o desempenho de nomeação do participante mantevese estável para as categorias animais (entre 75 e 100\% de acertos) e frutas (entre 50 e $75 \%$ de acertos), e para a categoria brinquedos, P1 apresentou $25 \%$ de acertos nas três sessões consecutivas.

$\mathrm{Na}$ avaliação inicial, a participante P2 não nomeou corretamente os estímulos das três categorias. Na categoria animais, a criança realizou duas sessões com ambos os pares (foca/peru e rena/tatu). Na segunda sessão, de ambos os pares, P2 atingiu o critério tanto no ensino de seleção quanto no teste de nomeação. Na sonda de aprendizagem, a participante nomeou corretamente a maioria das tentativas da categoria ensinada e manteve nulo o desempenho nas duas demais categorias. Na categoria frutas, P2 atingiu o critério tanto na seleção quanto na nomeação dos estímulos do primeiro par (coco/pera) na terceira sessão. Para o segundo par (figo/caju), a participante realizou quatro sessões e foi para o teste de nomeação quatro vezes, não atingindo o critério no teste. Na sonda de aprendizagem,

\section{Gabriela Aniceto e Lidia Maria Marson Postalli}

após o procedimento de ensino da categoria frutas, verificouse a manutenção do repertório aprendido na categoria animais, um aumento no percentual de nomeação correta dos estímulos da categoria frutas (50\%, 100\% e 100\% de acertos) e desempenho nulo na categoria brinquedos. Para o primeiro par (pipa/dado) da categoria brinquedos, P2 realizou duas sessões até atingir o critério no ensino de seleção e no teste de nomeação. Para o segundo par ensinado (peteca/ domino), a criança atingiu o critério na quarta sessão no ensino de seleção e no teste de nomeação. Na última sonda de aprendizagem, a participante P2 apresentou 100\% de acertos na nomeação dos estímulos das categorias animais e frutas e 75, 50 e $75 \%$ de acertos na nomeação dos estímulos da categoria brinquedos.

O participante P3 apresentou desempenho nulo na sonda inicial de nomeação para as três categorias de estímulos. $\mathrm{Na}$ categoria animais, P3 necessitou de três sessões para atingir o critério exigido. Em seguida, P3 nomeou todos os estímulos da categoria na sonda de nomeação e manteve nula a nomeação correspondente aos estímulos das duas demais categorias. Em relação à categoria frutas, P3 atingiu o critério na segunda sessão de ensino com os dois pares de estímulos. Na avaliação de nomeação dos estímulos das três categorias, P3 manteve $100 \%$ de acertos na nomeação dos estímulos da categoria animais, atingiu $75 \%$ de acertos na nomeação dos estímulos da categoria frutas e manteve nula a nomeação correta dos estímulos da categoria brinquedos. No primeiro par de brinquedos (pipa/dado), P3 atingiu o critério no ensino de seleção e no teste de nomeação na primeira sessão. Para o segundo par da categoria (peteca/ dominó), a criança realizou três sessões de ensino até atingir o critério no ensino de seleção e no teste de nomeação. $\mathrm{Na}$ sonda de aprendizagem, o participante apresentou $100 \%$ de acertos na nomeação dos estímulos das três categorias, exceto em uma sessão da categoria brinquedos.

$\mathrm{Na}$ avaliação inicial de nomeação, a participante P4 não nomeou corretamente os estímulos das categorias animais e frutas e nomeou corretamente um estímulo (pipa) da categoria brinquedos. Na categoria animais, P4 atingiu o critério na segunda sessão com o primeiro par (foca/peru). Para o segundo par, P4 atingiu o critério na primeira sessão. $\mathrm{Na}$ avaliação da nomeação após o ensino da categoria animais, P4 nomeou corretamente três animais (foca, peru e rena), manteve a nomeação de um brinquedo (pipa) e manteve nula a nomeação das frutas. No ensino da categoria frutas, para ambos os pares (coco/pera e figo/caju), P4 não atingiu o critério nas quatro sessões de ensino. Para o segundo par (figo/caju), a participante realizou duas vezes o bloco de nomeação, sem atingir o critério. Após o ensino da categoria de frutas, P4 manteve a nomeação dos animais (foca, tatu, rena e peru), apresentou nomeação parcial dos 


\section{-4: INTERACÃO EM LF PSICOLOGIA}

estímulos das frutas (pera, figo) e manteve a nomeação de um estímulo (pipa) da categoria brinquedos. No ensino da categoria brinquedos, para o primeiro par (pipa/dado), a criança atingiu o critério no ensino de seleção e no teste de nomeação na primeira sessão. Para o segundo par (peteca/ dominó), a criança atingiu o critério em cinco dos oito blocos de ensino de seleção, mas não atingiu o critério nos testes de nomeação. Na última sonda de aprendizagem, P4 nomeou corretamente os animais e as frutas e variou entre $25 \%$ a $100 \%$ de acertos na nomeação de brinquedos.

Na Tabela 2 é apresentada a nomeação dos estímulos experimentais pelas crianças nas avaliações de nomeação com as três categorias de estímulos. As variações acertos, trocas e omissões foram consideradas corretas pela pesquisadora, considerando que as crianças estavam em fase de aprendizagem da linguagem. Apenas quando não foi emitida nenhuma resposta, ou foi verbalizada uma palavra que não correspondia ao definido experimentalmente como correto, foi considerado erro. As trocas que ocorreram foram: "foga" ou "fota" em vez de "foca"; "pelu" em vez de "peru"; "fugo" em vez de "figo"; "pequeca" em vez de "peteca". A omissão de fonema foi verificada nos estímulos dado e dominó, os quais as crianças nomearam como "ado" e "minó", respectivamente.

\section{DISCUSSÃO}

Os resultados demonstraram que o ensino de seleção pode favorecer a nomeação de figuras por crianças. Os dados apresentaram variabilidade intra e interparticipantes, o mesmo participante atingiu o critério na discriminação condicional auditivo-visual e na nomeação de figuras para apenas algumas categorias ou pares de estímulos e houve diferença no desempenho nas tarefas entre os participantes. Por exemplo, P1, P2 e P4 atingiram o critério no ensino de seleção (100\%), porém não atingiram o critério nos testes de nomeação no segundo par de frutas (figo/caju). Verificou-se o mesmo fato em $\mathrm{P} 1$, o qual atingiu o critério no ensino de seleção do primeiro par de brinquedos (pipa/dado), mas não nos testes de nomeação. Na mesma categoria, com o segundo par de estímulo (peteca/dominó), P4 atingiu o critério em blocos de ensino de seleção, mas não nos testes de nomeação. P1 não atingiu o critério no ensino de seleção do segundo par de brinquedos e P3 atingiu esse critério, mas não o do teste de nomeação.

Não foram observadas diferenças significativas no desempenho dos participantes em função da idade, entretanto, verificou-se um desempenho estável e maior facilidade na realização das tarefas por participantes mais velhos. Os dados demonstram os efeitos do ensino da

\section{Gabriela Aniceto e Lidia Maria Marson Postalli}

seleção na nomeação de figuras, as crianças passaram a nomear o estímulo como determinado experimentalmente após o ensino das discriminações condicionais auditivovisual.

É importante destacar que nas avaliações de nomeação das figuras das três categorias (linha de base e sondas), mesmo sem correspondência com os definidos experimentalmente, as crianças nomeavam os estímulos. De modo geral, as crianças nomearam animais e frutas, mas apresentaram dificuldade na nomeação de brinquedos. Esse desempenho sugere variáveis importantes a serem investigadas: a familiaridade com os estímulos empregados, as constituições das palavras (dissílabas, trissílabas) e a extensão do procedimento (terceira categoria de ensino). Estudos futuros podem iniciar pelo ensino da categoria brinquedos, ou substituir por estímulos com palavras dissílabas, ou ainda substituir por uma categoria mais familiar para crianças nessa faixa etária.

Foram realizadas observações assistemáticas pela pesquisadora durante a condução da pesquisa, especificamente nos ensinos de seleção, nas quais pôde-se verificar que ao repetir o nome do estímulo, após a resposta correta da criança, as crianças ecoavam o nome dito pela pesquisadora, por exemplo, P1 ecoou "rena, coco, pera, caju, pipa e dado", P2 ecoou "peru, rena, tatu, pera, coco, figo, pipa e dado", P3 ecoou "rena, coco e pera" e P4 ecoou "coco, pera, figo, caju, dado, peteca e dominó". Pôde-se constatar que esse comportamento ecóico não garantiu a nomeação correta dos estímulos nos testes de nomeação. Também foi verificado que $\mathrm{P} 3$ foi a criança que menos ecoou, mas também foi a criança que precisou de menos sessões de ensino, atingindo o critério e mantendo elevados percentuais de acertos nas sondas de nomeação. Esses desempenhos estão de acordo com os indicados por Greer e Ross (2008) em que um dos primeiros operantes verbais aprendidos pelas crianças é o ecoico, podendo ser observado logo nas primeiras etapas de aprendizagem das primeiras palavras.

A participante P4 apresentou respostas intraverbais em duas situações do ensino de seleção, fazendo a nomeação correta ao selecionar o estímulo correto antes da pesquisadora. Por exemplo: "Pesquisadora: Parabéns! Este é o... Criança: coco. Pesquisadora: coco" e "Pesquisadora: Parabéns! Esta é a... Criança: pera. Pesquisador: pera". Outro aspecto interessante verificado durante a coleta de dados da participante P4 (29 meses), mesmo diante da seleção correta, do elogio da pesquisadora e da repetição do nome do estímulo, a participante discordou da pesquisadora em dois momentos durante as sessões de ensino, diante dos estímulos dominó ("Não! É controle") e peteca ("Não! É flor!). Destaca-se que a criança nomeou consistentemente os dois 
Tabela 2. Nomeação dos estimulos experimentais pelas crianças na linha de base e nas sondas

\begin{tabular}{|c|c|c|c|c|c|c|c|c|c|c|c|c|}
\hline & \multicolumn{3}{|c|}{ Linha de Base } & \multicolumn{3}{|c|}{ Sonda 1} & \multicolumn{3}{|c|}{ Sonda 2} & \multicolumn{3}{|c|}{ Sonda 3} \\
\hline & & & & & & & 21 & & & & & \\
\hline foca & $x$ & $x$ & $x$ & tatu & tatu & tatu & foca $a^{\star \star}$ & foca & foca** & foca ${ }^{\star \star}$ & foca** & foca** \\
\hline peru & patinho & patinho & patinho & patinho & $x$ & $x$ & peru** & foca & foca & peru** & peru** & foca \\
\hline rena & cavalo & cavalo & cavalo & rena** & rena** & rena** & rena** & rena** & rena** & rena** & rena** & rena** \\
\hline tatu & tartaruga & jacaré & tartaruga & tatu** & tatu** & tatu** & tatu** & tatu** & tatu** & tatu** & tatu** & tatu** \\
\hline pêra & maçã & maçã & maçã & maçã & maçã & maçã & pera** & pera** & pera** & pera** & 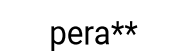 & 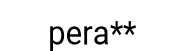 \\
\hline coco & $x$ & maçã & $x$ & faze papa & faze papa & faze papa & $\operatorname{coco} 0^{\star \star}$ & $\operatorname{coco} 0^{\star *}$ & $\operatorname{coco} 0^{\star *}$ & $\operatorname{coco} 0^{\star *}$ & $\operatorname{coco}^{\star \star *}$ & $\operatorname{coco} 0^{\star \star}$ \\
\hline figo & $x$ & $x$ & $x$ & faze papa & faze papa & faze papa & foca & garrafa & garrafa & fazer papa & garrafa & garrafa \\
\hline caju & maçã & maçã & $x$ & maçã & maçã & maçã & maçã & maçã & caju$^{\star *}$ & pera* & caju$^{\star \star}$ & caju** \\
\hline ріра & $x$ & $x$ & $x$ & florzinha & caicai balão & caicai balão & caicai balão & caicai balão & caicai balão & caicai balão & caicai balão & caicai balão \\
\hline dado & coração & coração & coração & coração & coração & coração & coração & coração & coração & 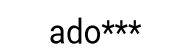 & ado*** & 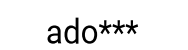 \\
\hline dominó & pecinha & pecinha & pecinha & pecinha & pecinha & pecinha & pecinha & pecinha & pecinha & pecinha & pecinha & pecinha \\
\hline peteca & $x$ & florzinha & $x$ & $x$ & caicai balão & caicai balão & florzinha & flor & florzinha & florzinha & florzinha & florzinha \\
\hline \multicolumn{13}{|c|}{$\mathrm{P} 2$} \\
\hline foca & peixe & peixe & peixe & foca** & foca** & tatu & foca** & foca** & foca** & foca** & foca** & foca** \\
\hline peru & pato & pato & pato & tatu * & tatu & tatu & 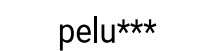 & 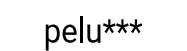 & 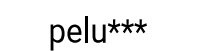 & 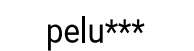 & 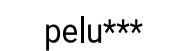 & 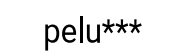 \\
\hline rena & cavalo & cavalo & cavalo & rena** & rena** & rena** & rena** & rena** & rena*ᄎ & rena** & rena** & rena*ᄎ \\
\hline tatu & cachorro & $x$ & au-au & $\operatorname{tatu}^{\star \star}$ & tatu** & tatu** & tatu** & tatu** & tatu** & tatu** & tatu** & tatu** \\
\hline pêra & $x$ & $x$ & maçã & maçã & maçã & maçã & pêra** & pera** & pera** & pera** & pera** & pera** \\
\hline coco & bola & maçã & morango & maçã & maçã & maçã & $\operatorname{coco}{ }^{\star *}$ & $\operatorname{coco} 0^{\star *}$ & $\operatorname{coco}{ }^{\star *}$ & $\operatorname{coco} 0^{\star *}$ & $\operatorname{coco}{ }^{\star \star}$ & $\operatorname{coco}{ }^{* *}$ \\
\hline figo & maçã & maçã & maçã & maçã & maçã & $x$ & pêra & 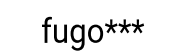 & 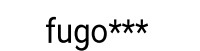 & 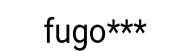 & 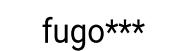 & 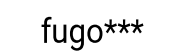 \\
\hline caju & morango & morango & maçã & maçã & maçã & maçã & flor & caju$^{\star \star}$ & caju** & caju** & caju$^{\star \star}$ & caju** \\
\hline pipa & balão & $x$ & balão & balão & balão & balão & balão & balão & balão & pipa** & balão* & pipa** \\
\hline dado & caixa & caixa & caixa & caixa & caixa & caixa & caixa & caixa & caixa & dado** & dado** & dado** \\
\hline dominó & $x$ & $x$ & controle & pecinha & caixa & peças & peças & pecinha & pecinhas & dado & caju & tatu \\
\hline peteca & $\tilde{n}$ sei & $x$ & flor & flor & flor & flor & flor & flor & flor & peteca** & 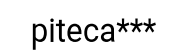 & 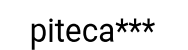 \\
\hline
\end{tabular}


(cont. Tab. 2)

P3

\begin{tabular}{|c|c|c|c|c|c|c|c|c|c|c|c|c|}
\hline & \multicolumn{3}{|c|}{ Linha de Base } & \multicolumn{3}{|c|}{ Sonda 1} & \multicolumn{3}{|c|}{ Sonda 2} & \multicolumn{3}{|c|}{ Sonda 3} \\
\hline foca & galo & galo & galo & 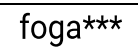 & foga $a * \star$ & 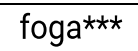 & foga $a \star \star$ & foga $a \star \star$ & foga $a * \star$ & foca** & foca*ᄎ & foga $a \star \star$ \\
\hline peru & galo & galo & galo & 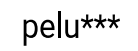 & 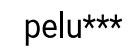 & 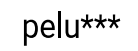 & 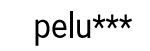 & pelu*** & 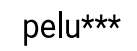 & 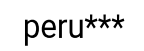 & 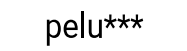 & 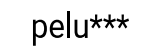 \\
\hline rena & cavalo & cavalo & cavalo & rena** & rena** & rena** & rena** & rena** & rena** & rena** & rena** & rena** \\
\hline tatu & lobo & lobo & lobo & tatu** & tatu** & tatu*ᄎ & tatu** & 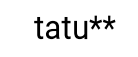 & tatu** & tatu** & tatu** & tatu** \\
\hline pêra & maçã & bola & maçã & maçã & bola & bola & pera** & pera** & pera ${ }^{\star \star}$ & pera** & pera** & pera** \\
\hline coco & bola & maçã & maçã & bola & bola & bola & $\operatorname{coco}{ }^{\star \star}$ & $\operatorname{coco}{ }^{* *}$ & $\operatorname{coco}{ }^{\star *}$ & $\operatorname{coco}{ }^{* *}$ & $\operatorname{coco}{ }^{\star *}$ & $\operatorname{coco} 0^{\star *}$ \\
\hline figo & maçã & bola & bola & maçã & bola & bola & figo** & figo** & figo** & figo** & figo** & figo** \\
\hline caju & bola & maçã & bola & bola & bola & bola & pera & caju** & pera & caju** & caju** & caju** \\
\hline pipa & flor & flor & flor & flor & flor & flor & flor & flor & flor & pipa** & pipa** & pipa** \\
\hline dado & bola & maçã & bola & bola & bola & bola & coco & bola & bola & dado** & dado** & dado** \\
\hline dominó & $x$ & $x$ & $x$ & peça & peça & $x$ & $x$ & $x$ & $x$ & 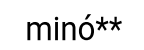 & dominó** & dominó** \\
\hline peteca & flor & flor & flor & flor & flor & flor & flor & flor & ave & peteca** & 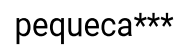 & pera \\
\hline \multicolumn{13}{|c|}{ P4 } \\
\hline foca & baleia & peixe & baleia & foca** & foca** & foca** & foca** & foca** & foca** & foca** & foca** & foca** \\
\hline peru & cocó & galo & cocó & peru** & peru** & peru** & cocó & 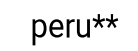 & peru** & peru** & peru** & peru** \\
\hline rena & cavalo & pcotó & pocotó & rena** & rena** & rena** & rena** & rena** & rena** & rena** & rena** & rena** \\
\hline tatu & jacaré & jacaré & jacaré & foca & peru & peru* & tatu** & tatu** & tatu** & tatu** & tatu** & tatu** \\
\hline pêra & $x$ & limão & limão & limão & maçã & maçã & pera** & 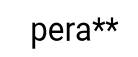 & 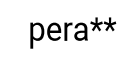 & pera** & pera** & figo** \\
\hline coco & maçã & $x$ & maçã & maçã & maçã & maçã & maçã & maçã & $\operatorname{coco}{ }^{* *}$ & $\operatorname{coc} 0^{\star *}$ & $\operatorname{coco}{ }^{* *}$ & $\operatorname{coco} \star \star$ \\
\hline figo & maçã & maçã & maçã & limão & maçã & maçã & coco & $x$ & figo** & figo** & figo** & figo** \\
\hline caju & tomate & morango & tomate & tomate & tomate & tomate & caju** & caju** & caju** & caju** & caju** & caju** \\
\hline pipa & pipa** & pipa** & pipa** & pipa** & cores & pipa** & pipa** & pipa** & pipa** & pipa** & pipa** & pipa** \\
\hline dado & caixa & caixa & $x$ & cores & cores & cores & cores & cores & cores & dado** & $\operatorname{coco}^{*}$ & dado** \\
\hline dominó & $x$ & $x$ & $x$ & controle & controle & controle & controle & controle & controle & controle & controle & 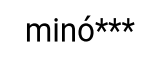 \\
\hline peteca & folha & folha & flor & flor & flor & cores & flor & florzi & florzi & flor & flor & queca*** \\
\hline
\end{tabular}

Legenda. Um asterisco indica autocorreção na nomeação do estímulo. Dois asteriscos indicam a nomeação com correspondência ponto a ponto. Três asteriscos indicam as nomeações com omissões ou trocas. 


\section{W INERACÄOEM ET PSICOLOGIA}

estímulos nas avaliações de linha de base e sondas como controle para dominó e flor para peteca.

Durante as sessões de ensino, após o acerto da criança seguido de um elogio pela pesquisadora e a confirmação do nome correto do estímulo "Esse aqui é o/a... (nome da figura)", três (P1, P2 e P4) das quatro crianças formularam perguntas para a pesquisadora, questionando se o nome emitido pela pesquisadora ao estímulo correspondia ao correto. Por exemplo, P1, na categoria brinquedos, após a pesquisadora apresentar o primeiro par de estímulo (pipa/ dado) e solicitar que a criança apontasse o estímulo visual correspondente ao estímulo auditivo dado, a criança apontou o dado. Após a resposta correta, o elogio da pesquisadora e o reforço "Este é o dado", a criança emitiu a seguinte a pergunta "É o dado?". Para fins de controle experimental, a pesquisadora não respondeu as perguntas das crianças.

As três (P1, P2 e P4) crianças também apresentaram autocorreções durante o ensino de seleção, os testes de nomeação e as sessões de sondagem. No ensino de seleção do primeiro par de animais (rena/tatu), a pesquisadora solicitou que P2 indicasse qual era a foca, P2 selecionou peru, porém, imediatamente, fez a autocorreção e selecionou a figura correta. Nos testes de nomeação, P1 nomeou de coração e de balão diante de dado e pipa, respectivamente, fazendo, em seguida, a nomeação correta. O mesmo foi observado com P2 na nomeação do estímulo pipa (nomeado como dado), mas logo se autocorrigiu. Nas sessões de sonda, os três participantes (P1, P2 e P4) também apresentaram autocorreção, sendo que P1 nomeou pera, ao invés de caju; P2 nomeou balão para o estímulo pipa e P4 nomeou o estímulo dado como coco. Nesta pesquisa, as autocorreções não foram consideradas como acerto.

No presente estudo, buscou-se garantir o controle experimental utilizando figuras desconhecidas de categorias possivelmente conhecidas pelas crianças. Essa estratégia difere de outros estudos apresentados nesta pesquisa (Bandini et al., 2012; Sousa et al., 2013), os quais utilizaram pseudopalavras como estímulo. Os resultados indicaram que o uso de figuras desconhecidas pelas crianças pode garantir o controle experimental, uma vez que as crianças passaram a nomear os estímulos, de acordo com o definido experimentalmente, após o ensino. O uso de figuras desconhecidas e palavras reais pode contribuir na ampliação de vocabulário e na generalização do conhecimento aprendido em situação experimental para outras situações de interação da criança.

Em relação à realização das sessões experimentais, notou-se que após a quarta tentativa, em especial no segundo bloco, a pesquisadora solicitava mais frequentemente a atenção das crianças para realização da

\section{Gabriela Aniceto e Lidia Maria Marson Postalli}

tarefa. Esses desempenhos estão de acordo com os indicados em estudos com crianças (Bandini et al., 2012; Sousa et al., 2013; Santos \& Souza, 2016). Sugere-se, para pesquisas futuras, que o procedimento seja planejado com passos menores em sessões de curta duração e em um único bloco de ensino de seleção e de teste de nomeação. Também se sugere que o ensino de seleção e os testes de nomeação sejam reduzidos para quatro tentativas por sessão, sendo duas para cada estímulo do par. Ainda, sugerese a inclusão de um pré-treino na etapa pré-experimental para familiarização com o contexto e com as tarefas experimentais, considerando que um dos participantes (P1) necessitou de ensino remediativo para familiarização com as tarefas a serem realizadas e com a condição experimental.

A presente investigação indica que o ensino de discriminações condicionais (tarefas de seleção/ comportamento de ouvinte) pode contribuir para nomeação de figuras (comportamento de falante) por crianças pequenas, de modo que ao ensinar a criança a selecionar/ apontar figuras (comportamento de ouvinte), a criança nomeia as figuras (comportamento de falante) sem o ensino direto. Destaca-se a necessidade de replicações para avaliar a generalidade dos resultados, sugere-se alterações metodológicas no procedimento de ensino, como redução do número de tentativas e de blocos por sessão. Com isso, o presente estudo indica futuras investigações que possam favorecer o aprimoramento do procedimento de ensino de relações nome e objeto e do repertório de nomeação por crianças.

\section{CONTRIBUIÇÃO DE CADA AUTOR}

Ambas as autoras participaram na concepção, coleta e análise de dados, redação e revisão do artigo.

\section{DECLARAÇÃO DE CONFLITOS DE INTERESSES}

As autoras declaram que não há conflito de interesse neste artigo.

\section{DECLARAÇÃO DE FINANCIAMENTO}

A segunda autora é pesquisadora do programa científico do Instituto Nacional de Ciência e Tecnologia sobre Comportamento, Cognição e Ensino (CNPq, Processo \#465686/2014-1) e Fundação de Apoio à Pesquisa do Estado de São Paulo (Proceso \#2014/50909-8). 


\section{INTERAÇÃO EM ET PSICOLOGIA}

\section{REFERÊNCIAS}

Acredolo, L., \& Goodwyn, S. (1988). Symbolic gesturing in normal infants. Child Development, 59 (2), 450-466. doi: $10.2307 / 1130324$

Anastácio-Pessan, F. L., Almeida-Verdu, A. C. M., Bevilacqua, M. C., \& Souza, D. G. (2015). Usando o Paradigma de Equivalência para Aumentar a Correspondência na Fala de Crianças com Implante Coclear na Nomeação de Figuras e na Leitura. Psicologia: Refexão e Crítica, 28(2), 365-377. doi: 10.1590/1678-7153.201528217

Aquino, F. S. B., \& Salomão, N. M. R. (2010). Intencionalidade comunicativa: teorias e implicações para a cognição social infantil. Estudos de Psicologia, 27(3), 413-420. doi: 10.1590/S0103-166X2010000300013

Arntzen, E., \& Almas I. K. (2002). Effects of mand-tact versus tact-only training on the acquisition of tacts. Journal of Applied Behavior Analysis, 35(4), 419-422. doi: 10.1901/ jaba.2002.35-419

Bandini, C. S. M., Sella, A. C., Postalli, L. M. M, Bandini, H. H. M., \& Silva, E. T. P. (2012). Effects of Selection Tasks on Naming Emergence in Children. Psicologia: Reflexão e Crítica, 25(3), 568-577. doi: 10.1590/S010279722012000300017

Bates, E. (1979). The emergence of symbols: Cognition and communication in infancy. Nova lorque: Academic Press.

Bee, H., \& Boyd, D. A criança em desenvolvimento. Porto Alegre: Artmed, 2011.

Capovilla, F. C., Negrão, V. B., \& Damázio, M. (2011). Teste de Vocabulário Auditivo e Teste de Vocabulário Expressivo: validados e normatizados para o desenvolvimento da compreensão a fala dos 18 meses aos seis anos de idade. São Paulo: Memnon.

Carroll, R. J., \& Hesse, B. E. (1987). The effects of alternating mand and tact training on the acquisition of tacts. The Analysis of Verbal Behavior, 5, 55-65. doi: 10.1007/ BF03392820

Frankenburg, W. K., Dodds, J.; Archer, P., Shapiro, H., \& Bresnick, B. (1992). The Denver II: A major revision and restandardization of the Denver Developmental Screening Test. Pediatrics, 89(1), 91-97.

Gast, D. L., \& Ledford, J. (2010). Multiple Baseline and Multiple Probe Designs. In: D.L. Gast (Org.), Single Subject Research Methodology in Behavioral Sciences (pp. 226328). Nova lorque: Routledge.

Greer, R. D., \& Ross, D. E. (2008). Verbal Behavior Analysis: Inducing and expanding new verbal capabilities in children with Language Delays. Nova lorque: Pearson.
Gabriela Aniceto e Lidia Maria Marson Postalli

Greer, R. D., \& Speckman, J. (2009). The integration of speaker and listener response: a theory of verbal development. The Psychological Record, 59(3), 449-488. doi: 10.1007/ BF03395674

Gomes, M. L. C., Benitez, P., Domeniconi, C., \& Almeida-Verdu, A. C. M. (2017). Efeitos do ensino do ecoico aliado a repertórios básicos de leitura sobre a nomeação de palavras em crianças com deficiência intellectual. Temas em Psicologia, 25(1), 319-334. doi: 10.9788/TP2017.1$18 \mathrm{Pt}$

Goodwyn, S. W., Acredolo, L. P., \& Brown, C. A. (2000). Impact of symbolic gesturing on early language development. Journal of Nonverbal Behavior, 24(2), 81-103. doi: 10.1023/ A: 1006653828895

Gurteen, P. M., Horne, P. J., \& Erjavec, M. (2011). Rapid word learning in 13- and 17-month olds in a naturalistic twoword procedure: Looking versus reaching measures. Journal of Experimental Child Psychology, 109(2), 201-217. doi: 10.1016/j.jecp.2010.12.001

Hoff, E. (1996). Language Development. Belmont: Cengage Learning.

Hussein, L. G., Góes, C. C., Chiodelli, T., Silva-Marinho, C. S. O., Gonçalves, F. L., \& Almeida-Verdu, A. C. M. (2018). Aquisição do comportamento de ouvir, baseada em seleção de figuras, em crianças com implante coclear contralateral. Revista Brasileira de Terapia Comportamental e Cognitiva, 20(1), 27-39. doi: 10.31505/ rbtcc.v20i1.1135

Kazdin, A. E. (1982). Single-case research designs: Methods for clinical and applied settings. Nova lorque: Oxford University Press.

Lamarre, J., \& Holland J. G. (1985). The functional independence of mands and tacts. Journal of the Experimental Analysis of Behavior, 43(1), 5-19. doi: 10.1901/jeab.1985.43-5

Lamprecht, R. R., Bonilha, G. F. G., Freitas, G. C. M., Matzenauer, C. L. B. Mezzomo, C. L., Oliveira, C. C., \& Ribas, L. P. (2004). Aquisição Fonológica do Português Perfil de desenvolvimento e subsídios para terapia. São Paulo: Artmed.

Löhr, T. \& Gil, M. S. C. A. (2015). Learning by playing: echo and tact in expanding the verbal repertoire of infants. Paideia, 25(60), 77-85. doi: 10.1590/1982-43272560201510

McLaughlin, S. F. (2010). Verbal Behavior by B.F. Skinner: Contributions to Analyzing Early Language Learning. The Journal of Speech and Language Pathology, 5(2), 114-131. doi: $10.1037 / \mathrm{h} 0100272$

Newcombe, N. (1999) Desenvolvimento Infantil - Abordagem de Mussen. Porto Alegre: Artmed. 


\section{-4: INTERACÃO EM IT PSICOLOGIA}

Oliveira, T. P., \& Gil, M. S. C. A. (2007). Elementos fundamentais para a aquisição de operantes por bebês: análise comportamental da "atenção compartilhada". Revista Brasileira de Terapia Comportamental e Cognitiva, 9(2), 217-225. doi: 10.31505/rbtcc.v9i2.195

Petursdottir, A. I., Carr, J. E., \& Michael, J. (2005). Emergence of mands and tacts of novel objects among preschool children. The Analysis of Verbal Behavior, 21(1), 59-74. doi: 10.1007/BF03393010

Santos, C. A., Neves, A. J., Silva, M. G. C., \& Almeida-Verdu, A. C. M. (2014). Efeitos da aprendizagem da relação entre palavra ditada e figura sobre a nomeação de figuras: relações entre o ouvir e o falar. Psicologia em Revista, 20(3), 566-581. doi: 10.5752/P.16789523.2014V20N3P566

Santos, E. L. N., \& Souza, C. B. A. (2016). Ensino de nomeação com objetos e figuras para crianças com autismo. Psicologia: Teoria e Pesquisa, 32(3), 1-10. doi: 10.1590/0102-3772e32329

\section{Gabriela Aniceto e Lidia Maria Marson Postalli}

Sousa, N. M., Souza, C. B. A., \& Gil, M. S. C. A. (2013). Aprendizagem rápida de comportamento de ouvinte por um bebê. Interação em Psicologia, 17(1), 67-78. doi: 10.5380/psi.v17i1.28205

Souza, F. B., Almeida-Verdu, A. C. M., \& Bevilacqua, M. C. (2013). Ecoico e nomeação de figuras em crianças com deficiência auditiva pré-lingual com implante coclear. Acta Comportamentalia, 21(3), 325-339.

Skinner, B. F. (1957). O comportamento verbal. São Paulo: Cultrix. 